\title{
COMPLICATIONS OF RECURRENT CHOLESTEATOMA: A CASE REPORT
}

\author{
C. V. Srinivas ${ }^{1}$, Vidya $\mathrm{H}^{2}$
}

\section{HOW TO CITE THIS ARTICLE:}

C. V. Srinivas, Vidya H. "Complications of Recurrent Cholesteatoma: A Case Report". Journal of Evolution of Medical and Dental Sciences 2015; Vol. 4, Issue 64, August 10; Page: 11260-11265,

DOI: $10.14260 /$ jemds/2015/1623

\begin{abstract}
Chronic suppurative otitis media, infection of the middle ear cleft, is a common disease in the developing countries and the complications associated with it still pose a major problem. The proximity of the middle ear cleft and mastoid air cells to the extracranial and intracranial compartments places structures located in these areas at increased risk of complications. We report a case of recurrent cholesteatoma in a patient presenting with intracranial complications and facial nerve palsy.
\end{abstract}

KEYWORDS: Cholesteatoma, Intracranial complications, Facial nerve palsy.

INTRODUCTION: Chronic suppurative otitis media (CSOM) is one of the most commonly treated infections in clinical practice today. It is a sequel of acute otitis media (AOM) which is again a common infection in childhood. Most of the cases of AOM do well with antibiotic therapy. In those who fail to receive antibiotic or fail to respond to antibiotic therapy, CSOM results. In pre-antibiotic era, AOM resulted in intratemporal and intracranial complications, now with introduction of antibiotic therapy the incidence of complications has come down. However cases of CSOM still develop these complications even in this era of antibiotic therapy. ${ }^{1}$

CSOM is broadly classified into tubotympanic (Otitis media without cholesteatoma) and atticoantral (Otitis media with cholesteatoma) type. Cholesteatoma is a pocket or cystic lesion lined by stratified squamous epithelium containing proliferative keratin within the temporal bone, most frequently involves the middle ear cleft. The invasive expansion and the keratin accumulation may cause bony destruction, hearing impairment, facial nerve paralysis, labyrinthine fistula, as well as intracranial complications such as brain abscess and meningitis.

Facial nerve follows a course within the temporal bone, has 4 segments: Meatal, labyrinthine, tympanic, and mastoid. The tympanic and mastoid segments are mostly vulnerable to injury during otologic surgery. ${ }^{2,3}$ Destruction of the bony fallopian canal covering the nerve can occur as a result of pathologic or surgical invasions.

CASE REPORT: 24 years old female patient had presented with complaints of left ear discharge (Mucopurulent and foul smelling), fever (Intermittent type and moderate grade) and headache (severe throbbing type predominantly left side) since 10 days. Patient had bouts of projectile vomiting since 8 days, double vision since 6 days and one episode of generalized tonic clonic seizure lasting for 3-5 minutes 4 days back. Patient also gives history of left ear surgery at the age of 7 . Examination of the ear revealed purulent discharge in the EAC.

Neurologically she was conscious, alert with GCS- E4 V5 M6 (15/15). Pupils were bilaterally equal and reacting to light. She had bilateral $6^{\text {th }}$ nerve palsy with left LMN facial palsy. Horizontal nystagmus present. Right hemiparesis of grade 4/5. Deep tendon reflexes were sluggish. Neck stiffness was present. 


\section{CASE REPORT}

CT scan brain (Plain and contrast) showed left tentorial and posterior interhemispheric subdural empyema with left squamous temporal bone erosion. (Figure 1).

Figure 1: Shows left tentorial and posterior interhemispheric subdural empyema.

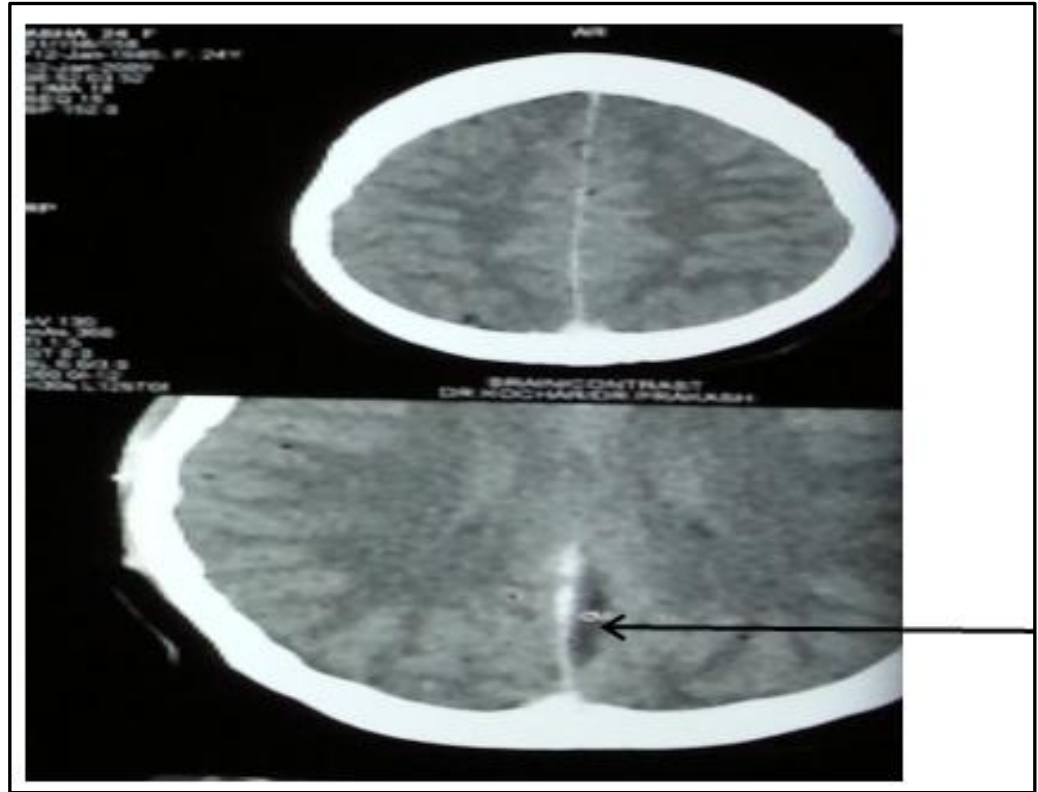

Fig. 1

MRI brain done 11 days after CT scan showed left CSOM with complete opacification of the mastoid and middle ear cavity with fluid and granulation tissue. Subdural collection in the posterior interhemispheric region and extending to the left parietal region suggestive of an empyema with osseous breach. Multiple acute infracts in the posterior fossa. (Figure 2)

Figure 2: shows subdural collection in the posterior interhemispheric region and left parietal region) MR Venography of brain showed left transverse and sigmoid sinus thrombosis indicating extension of infection from left mastoid abscess. (Figure 3).

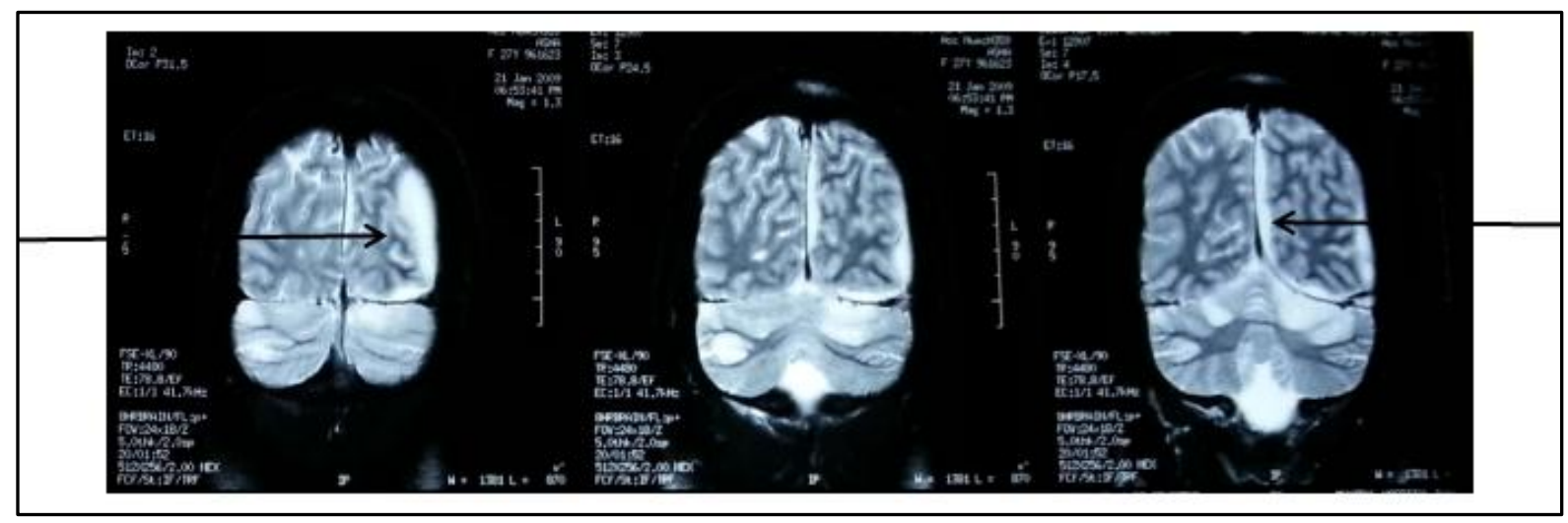

\section{Fig. 2}




\section{CASE REPORT}

Figure 3: Shows left transverse and sigmoid sinus thrombosis.

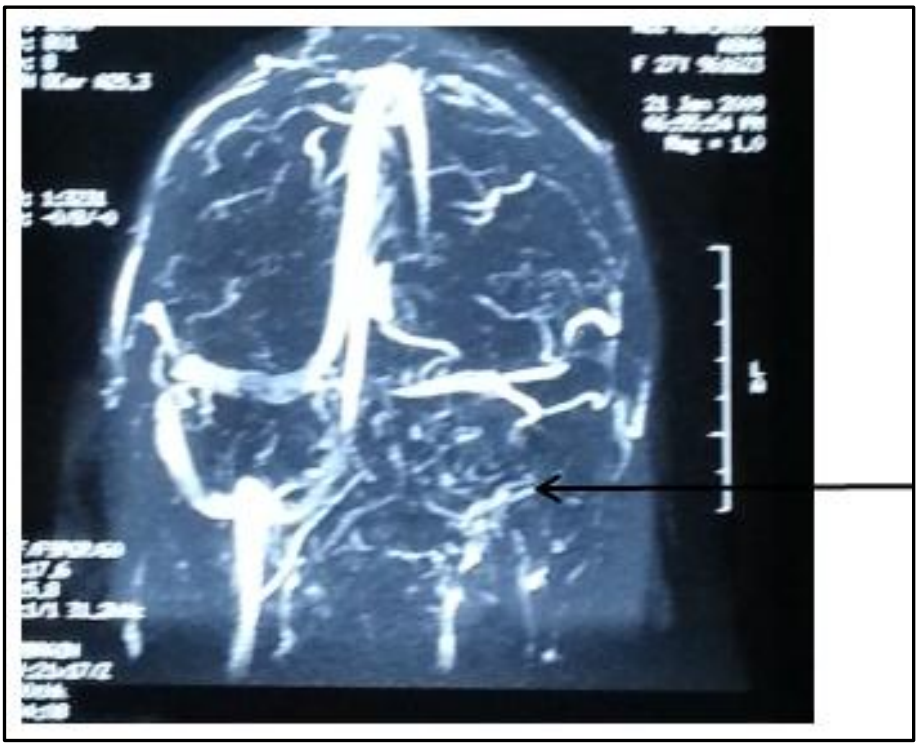

\section{Fig. 3}

Patient was managed with antimeningitic dose of antibiotics, anticonvulsants, antiedema and low molecular weight heparin and limb physiotherapy. Once the intracranial complications were managed, left ear mastoid exploration was planned. Intraoperatively, previously done MRM cavity examined. Large cholesteatoma sac in the mastoid cavity and middle ear removed. Sinus plate, tegmen plate and bony fallopian canal covering the mastoid segment of facial nerve was eroded by the cholesteatoma (Figure 4). Exposed facial nerve segment was covered by temporalis fascia graft. Exposed dura covered with gelfoam, mastoid cavity obliterated and wide meatoplasty was done. Post operatively facial nerve function was normal (Figure 5).

Figure 4: Shows exposed mastoid segment of facial nerve following erosion of bony canal.

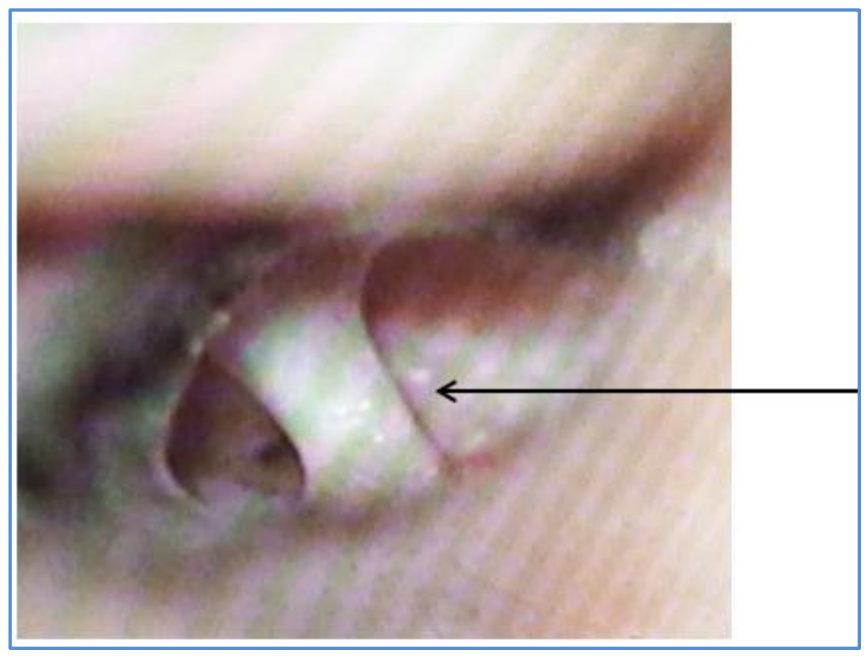

\section{Fig. 4}




\section{POST-OPERATIVE FOLLOW UP:}

Figure 5: Post-operative follow up with complete recovery of facial nerve function.

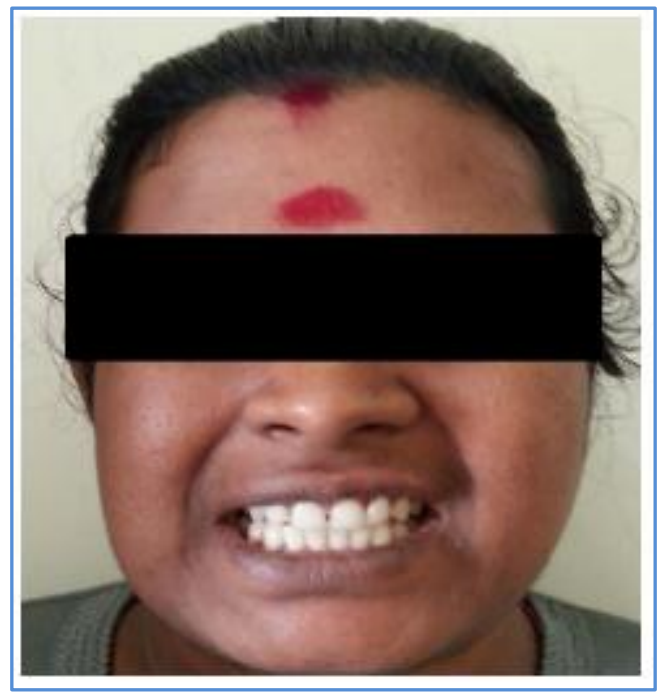

\section{Fig. 5}

DISCUSSION: Chronic otitis media still prevails as one of the most common otological problems encountered worldwide especially in the developing countries. Global burden of CSOM obtained from various prevalence surveys across the different countries shows that 65-330 million individuals are suffering from the disease. 39-220 million people suffer from hearing impairment caused by the disease. ${ }^{1}$

Complications of CSOM are broadly classified into intratemporal (Coalescent mastoidoitis, facial nerve palsy, labyrinthitis and petrous apicitis) and intracranial complications (Meningitis, Extradural abscess, Subdural abscess, Brain abscess, Sigmoid sinus thrombosis and Otitic hydrocephalus). ${ }^{1}$

The mechanism of the bony destruction in cholesteatoma remains controversial, suggested theories are pressure necrosis, osteolysis or contact between the inflammatory granulation tissue and bone, which cause a series of enzymatic bony destructions. 4,5

Facial nerve paralysis is uncommon but significant complication of CSOM. It has decreased significantly with the use of newer diagnostic tools and effective antibiotics. ${ }^{6}$ The frequency of facial nerve paralysis in chronic otitis media may range from 0.16 to $5.1 \% .^{7}$ The mechanism of facial nerve paralysis is not fully understood. It is often associated with dehiscence in the fallopian canal. ${ }^{8}$ Some of the proposed etiologic factors may be osteitis, bone erosion, external compression, edema and inflammation of the nerve by bacteria or neurotoxins. ${ }^{9}$ Facial nerve paralysis due to chronic otitis media may present either abruptly or gradually. Gradual onset results most commonly due to compression from cholesteatoma. ${ }^{10}$

Patients with facial palsy as a result of chronic otitis media should be operated on as early as possible without regard to the severity of facial function, presence of cholesteatoma, type of onset, age of the patient and any previous otologic surgical history. The duration of onset of facial palsy to the time of surgery is important, as longer duration leads to severe deterioration of the facial nerve and poor surgical outcomes. ${ }^{11}$ 
Modified radical mastoidectomy with canal wall down procedure is the most common surgical technique used for eradication of disease as well as facial nerve decompression. This ensures removal of extensive cholesteatoma and granulation tissue and frequent inspection of the cavity to rule out recurrence. 12

High surgical gain is defined as improvement in facial function by two or more grades by House-Brackmann grading system after surgery.6,11 Good recovery is seen in cases of chronic suppurative otitis media with short duration of onset of facial nerve paralysis, absence of previous surgery, noncholesteatomatous inflammatory granulation tissue and a healthy bony labyrinth. ${ }^{9}$

Presenting complaints of the patient can help to arrive at a provisional diagnosis of intracranial or intratemporal complication of CSOM. CT scan of temporal bone and brain gives information regarding the extent of the disease and presence of bony erosion. Mortality rates from intracranial complications have also fallen significantly from $35 \%$ to $5 \%$.

CONCLUSION: Although the incidence of complications of CSOM has decreased in recent decades, it remains too high. Excessive use and misuse of antibiotic treatment may cause masked presentations, thereby reducing the diagnosis. It is critical that clinicians remain alert for clinical signs and symptoms that may indicate the onset of these potentially serious complications and be prepared to examine patients for the presence of more than one complication. Modern diagnostic techniques with appropriate medical and surgical treatment is necessary to reduce mortality.

\section{REFERENCES:}

1. Chandrashekharayya SH. Complications of chronic suppurative otitis media- still a menace. Med Inn 2013; 2: 3-4.

2. Bayazit YA, Ozer E, Kanlikama M. Gross dehiscence of the bone covering the facial nerve in the light of otological surgery. J Laryngol Otol. 2002; 116: 800-803.

3. Green JD Jr, Shelton C, Brackmann DE. Iatrogenic facial nerve injury during otologic surgery. Laryngoscope. 1994; 104:922-926.

4. Nilssen E, Wormald P. Facial nerve palsy in mastoid surgery. J Laryngol Otol 1997; 111: 113116.

5. Wiet RJ. Iatrogenic facial paralysis. Otolaryngol Clin North Am 1982; 15: 773-780.

6. House JW, Brackmann DE. Facial nerve grading system. Otolaryngol Head Neck Surg 1985; 93: 146-7.

7. Savic DL, Djeric DR. Facial nerve paralysis in chronic suppurative otitis media. Clin Otolaryngol Allied Sci 1989; 14: 515-7.

8. Ceylan A, Bayazit Y, Yilmaz M, Celenk F, BayramogluI, Uygur K, Goksu N, Ozbilen S, Akyildiz I, Korkuyu E. Extracranial complications of chronic otitis media. Int Adv Otol 2009; 5: (1) 51-55.

9. Kim J, Jung G, Park S, Lee WS. Facial nerve paralysis due to chronic otitis media: Prognosis in restoration of facial function after surgical intervention. Yonsei Med J 2012; 53 (3): 642-648.

10. Altuntas A, Unal A, Aslan A, Ozcan M, Kurkcuoglu S, Nalca Y. Facial nerve paralysis in chronic suppurative otitis media: Ankara Numune Hospital experience. Auris Nasus Larynx 1998; 25: 169-72.

11. Ikeda M, Nakazato H, Onoda K, Hirai R, Kida A. Facial nerve paralysis caused by middle ear cholesteatoma and effects of surgical intervention. Acta Otolaryngol 2006; 126: 95-100. 


\section{CASE REPORT}

12. Glasscock, BC Decker Inc, Surgery of the ear, 5th ed, Elsevier Ontario 2003: Surgery of the facial nerve- Samy RN and Gantz BJ, 615.

\section{AUTHORS:}

1. C. V. Srinivas

2. Vidya $\mathrm{H}$.

\section{PARTICULARS OF CONTRIBUTORS:}

1. Associate Professor, Department of ENT, Dr. B. R. Ambedkar Medical College, Bangalore.

2. Junior Resident, Department of ENT, Dr. B. R. Ambedkar Medical College, Bangalore.

FINANCIAL OR OTHER

COMPETING INTERESTS: None

\section{NAME ADDRESS EMAIL ID OF THE CORRESPONDING AUTHOR:}

Dr. C. V. Srinivas, No. 5A, $3^{\text {rd }} B$ Main, $4^{\text {th }}$ A Cross, $3^{\text {rd }}$ Block, HRBR Layout, Kalyan Nagar,

Bangalore-43.

E-mail: game_sri@yahoo.com

Date of Submission: 20/07/2015.

Date of Peer Review: 21/07/2015.

Date of Acceptance: 04/08/2015.

Date of Publishing: 10/08/2015. 